\title{
Meta-Analysis of the Influence of Chronic Kidney Disease on the Risk of Thromboembolism Among Patients With Nonvalvular Atrial Fibrillation
}

\author{
Rui Providência, MD, MSc ${ }^{\mathrm{a}, \mathrm{b}}$, , Eloi Marijon, $\mathrm{MD}, \mathrm{PhD}^{\mathrm{c}}$, Serge Boveda, $\mathrm{MD}^{\mathrm{a}}$, Sérgio Barra, $\mathrm{MD}^{\mathrm{d}}$, \\ Kumar Narayanan, MD ${ }^{\mathrm{c}, \mathrm{e}}$, Jean-Yves Le Heuzey, MD ${ }^{\mathrm{c}}$, Bernard J. Gersh, MBChB, DPhil ${ }^{\mathrm{f}}$, \\ and Lino Gonçalves, $\mathrm{MD}, \mathrm{PhD}^{\mathrm{b}}$
}

\begin{abstract}
Chronic kidney disease (CKD) and atrial fibrillation (AF) frequently coexist. However, the extent to which CKD increases the risk of thromboembolism in patients with nonvalvular $\mathrm{AF}$ and the benefits of anticoagulation in this group remain unclear. We addressed the role of CKD in the prediction of thromboembolic events and the impact of anticoagulation using a meta-analysis method. Data sources included MEDLINE, EMBASE, and Cochrane (from inception to January 2014). Three independent reviewers selected studies. Descriptive and quantitative information was extracted from each selected study and a random-effects meta-analysis was performed. After screening 962 search results, 19 studies were considered eligible. Among patients with AF, the presence of CKD resulted in an increased risk of thromboembolism (hazard ratio [HR] 1.46, 95\% confidence interval [CI] 1.20 to 1.76 , $\mathrm{p}=0.0001$ ), particularly in case of end-stage CKD (HR 1.83, 95\% CI 1.56 to 2.14, $\mathrm{p}<0.00001)$. Warfarin decreased the incidence of thromboembolic events in patients with non-end-stage CKD (HR 0.39, 95\% CI 0.18 to 0.86 , p <0.00001). Recent data on novel oral anticoagulants suggested a higher efficacy of these agents compared with warfarin (HR $0.80,95 \% \mathrm{CI} 0.66$ to $0.96, \mathrm{p}=0.02$ ) and aspirin (HR $0.32,95 \% \mathrm{CI} 0.19$ to $0.55, \mathrm{p}<0.0001)$ in treating non-end-stage CKD. In conclusion, the presence of CKD in patients with AF is associated with an almost 50\% increased thromboembolic risk, which can be effectively decreased with appropriate antithrombotic therapy. Further prospective studies are needed to better evaluate the interest of anticoagulation in patients with severe CKD. (c) 2014 Elsevier Inc. All rights reserved. (Am J Cardiol 2014;114:646-653)
\end{abstract}

Thromboembolic events are one of the most feared complications of atrial fibrillation (AF). ${ }^{1}$ Chronic kidney disease (CKD) is relatively prevalent in patients with $\mathrm{AF}^{2}$ The extent to which the presence of CKD may increase the risk of thromboembolism in patients with AF has not yet been fully elucidated. Oral anticoagulation is the mainstay of thromboembolic prevention in patients with $\mathrm{AF}^{3}$ but data on efficacy and safety in the CKD and dialysis population have been scarce and contradictory. ${ }^{4,5}$ Our aim was to systematically evaluate, through a meta-analysis method, the impact of the presence of CKD in patients with AF as regards risk of thromboembolism and the potential benefit of anticoagulation in that setting.

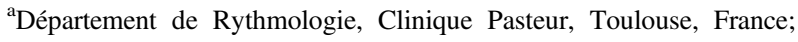
${ }^{b}$ Faculty of Medicine, University of Coimbra, Coimbra, Portugal; ${ }^{c}$ Paris Descartes University and European Georges Pompidou Hospital, Paris, France; ${ }^{\mathrm{d}}$ Papworth Hospital NHS Foundation Trust, Cambridge, United Kingdom; ${ }^{\text {H} H e a r t ~ I n s t i t u t e, ~ C e d a r s-S i n a i ~ M e d i c a l ~ C e n t e r, ~ L o s ~ A n g e l e s, ~}$ California; and ${ }^{\mathrm{f}}$ Mayo Clinic, Rochester, Minnesota. Manuscript received April 9, 2014; revised manuscript received and accepted May 27, 2014.

See page 652 for disclosure information.

*Corresponding author: Tel: (+33) 5622116 45; fax: (+33) 56221 1641.

E-mail address: rui_providencia@yahoo.com (R. Providência).
}

\section{Methods}

We performed a search in MEDLINE (by way of Ovid and PubMed), EMBASE, and Cochrane (from inception to January 3, 2014) databases using the following search string: "atrial fibrillation" AND ("renal failure" OR "chronic renal disease" OR "dialysis") AND ("stroke" OR "thromboembolism"). The reference lists of the accessed full-text reports were further researched for sources of potential information relevant to this analysis. The authors of full-text reports and abstracts were contacted by e-mail to retrieve additional information.

Only longitudinal studies assessing the occurrence of a composite end point of stroke or systemic embolism (and including transient ischemic attack) during follow-up in patients with $\mathrm{AF}$ were considered for inclusion. Both registries and randomized trials were considered eligible for analysis. The methods sections of evaluated studies were reviewed to confirm the suitability and composition of the reported end point. Studies assessing only stroke (either ischemic, hemorrhagic, or a composite of both) and providing no data on systemic embolism were not considered representative of the full spectrum of thromboembolism in AF and were excluded from analysis. Similarly, studies only reporting stroke or systemic embolism in association with myocardial infarction, hospitalization, or death not due to stroke or systemic embolism were not included. 
Search on MEDLINE (via OVID and PubMED), EMBASE and COCHRANE (from inception to $3^{\text {rd }}$ January 2014) using the following search string:

"atrial fibrillation" AND ("renal failure" OR "chronic kidney disease" OR "dialysis") AND ("stroke" OR "thromboembolism")

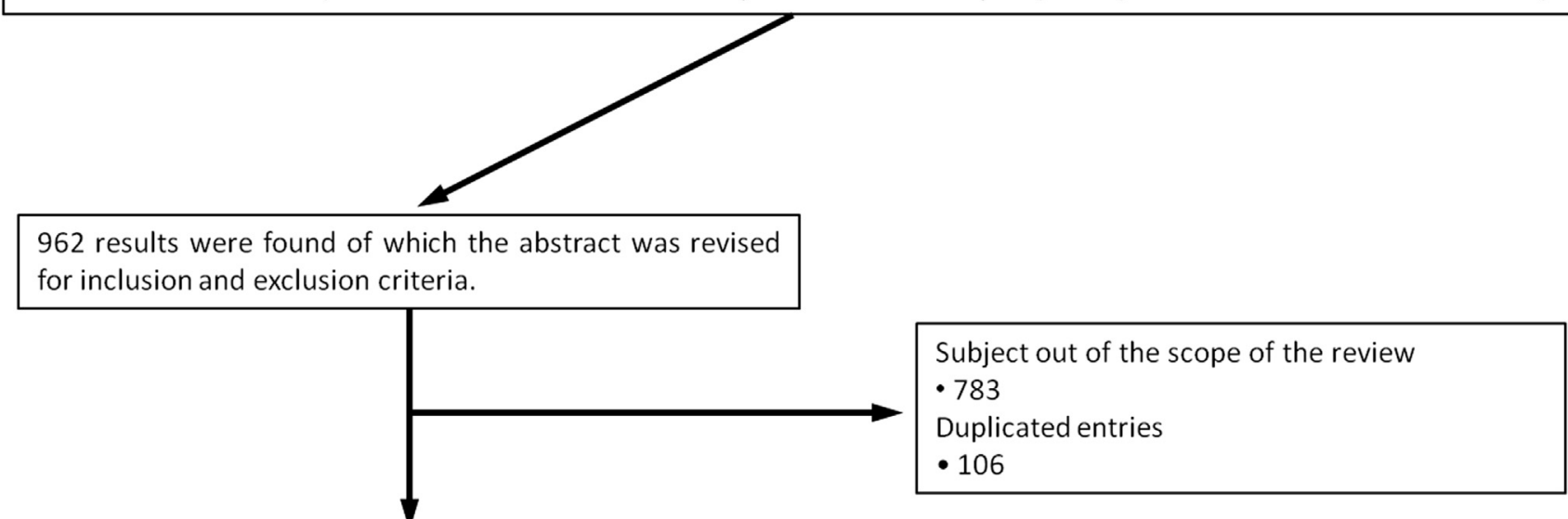

73 results possibly addressing the purpose of the review of which the full manuscript was revised or abstract (if conference abstract) for inclusion and exclusion criteria.

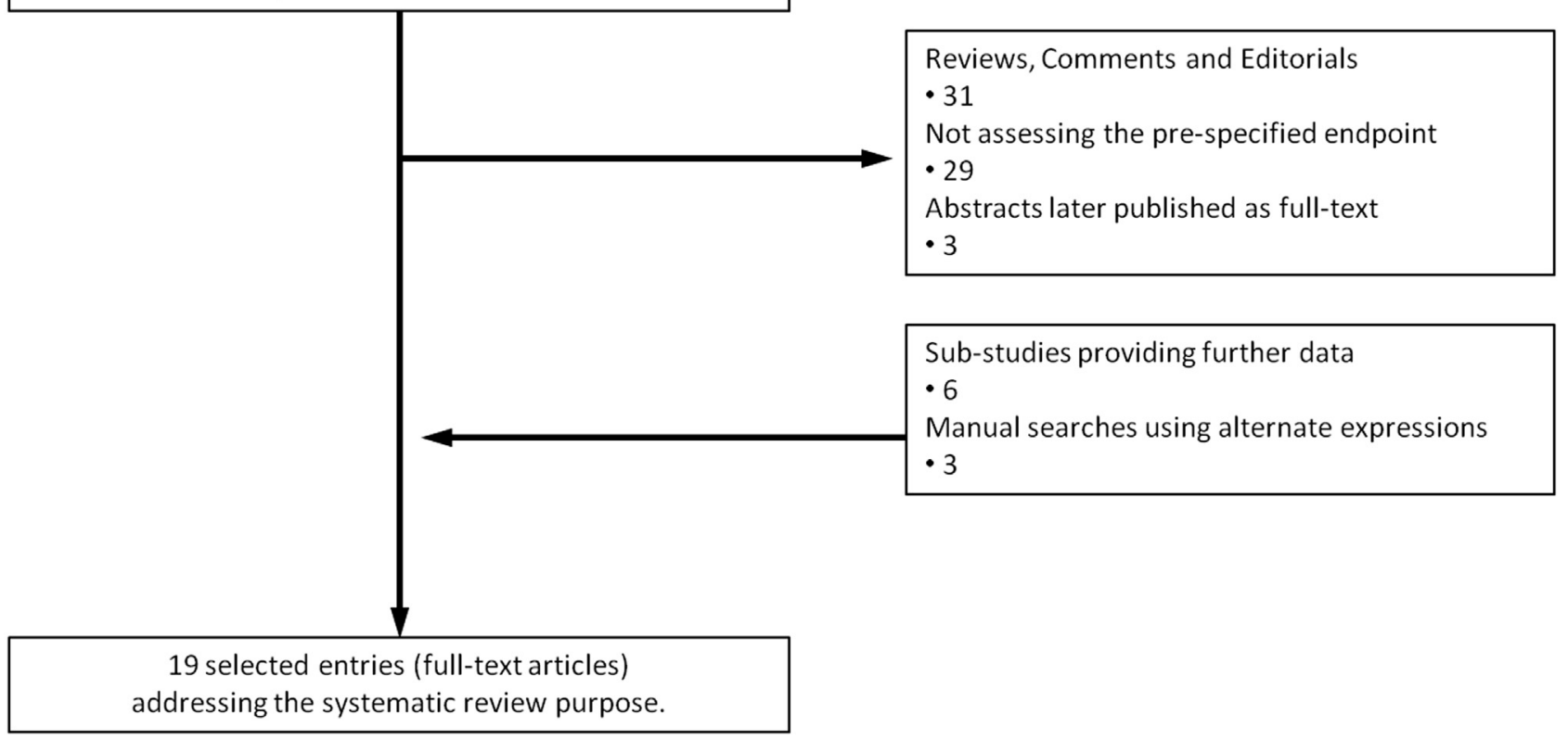

Figure 1. Flowchart diagram illustrating study selection.

To be included in the systematic review, the studies needed to have a design allowing extraction of information concerning at least 1 of the 2 main aims of this study: (1) assessment of the incidence of stroke and systemic embolism in patients with AF according to the presence of CKD (including dialysis treatment) and (2) estimating the impact of anticoagulation in patients with CKD and AF. The population, intervention, comparison, and outcome approach was used for this aim. ${ }^{6}$ The population of interest included patients with nonvalvular AF with CKD or treated with dialysis. The term end-stage CKD was used for patients with disease requiring renal replacement therapy, either dialysis or transplantation. Non-end-stage CKD was used for the remaining patients with renal disease. The intervention was anticoagulation. Comparisons were performed among the following groups: adjusted-dose warfarin (target international normalized ratio of 2 to 3 ) versus no treatment, aspirin or low dosage non-adjusted-dose warfarin (target international normalized ratio $<1.5$ ); warfarin versus novel oral anticoagulants; and novel oral anticoagulants versus aspirin. The outcome has been defined previously.

Two independent reviewers (RP and SCB) screened all abstracts and titles to identify potentially eligible studies. The full text of these potentially eligible studies was then evaluated to determine the eligibility of the study for the review and meta-analysis. Disagreements regarding eligibility were resolved by consensus with the help of a third reviewer $(\mathrm{SB})$.

Data extraction and presentation for the preparation of this report followed the recommendations of the Preferred 
Table 1

Selected studies for the systematic review: baseline information and main findings

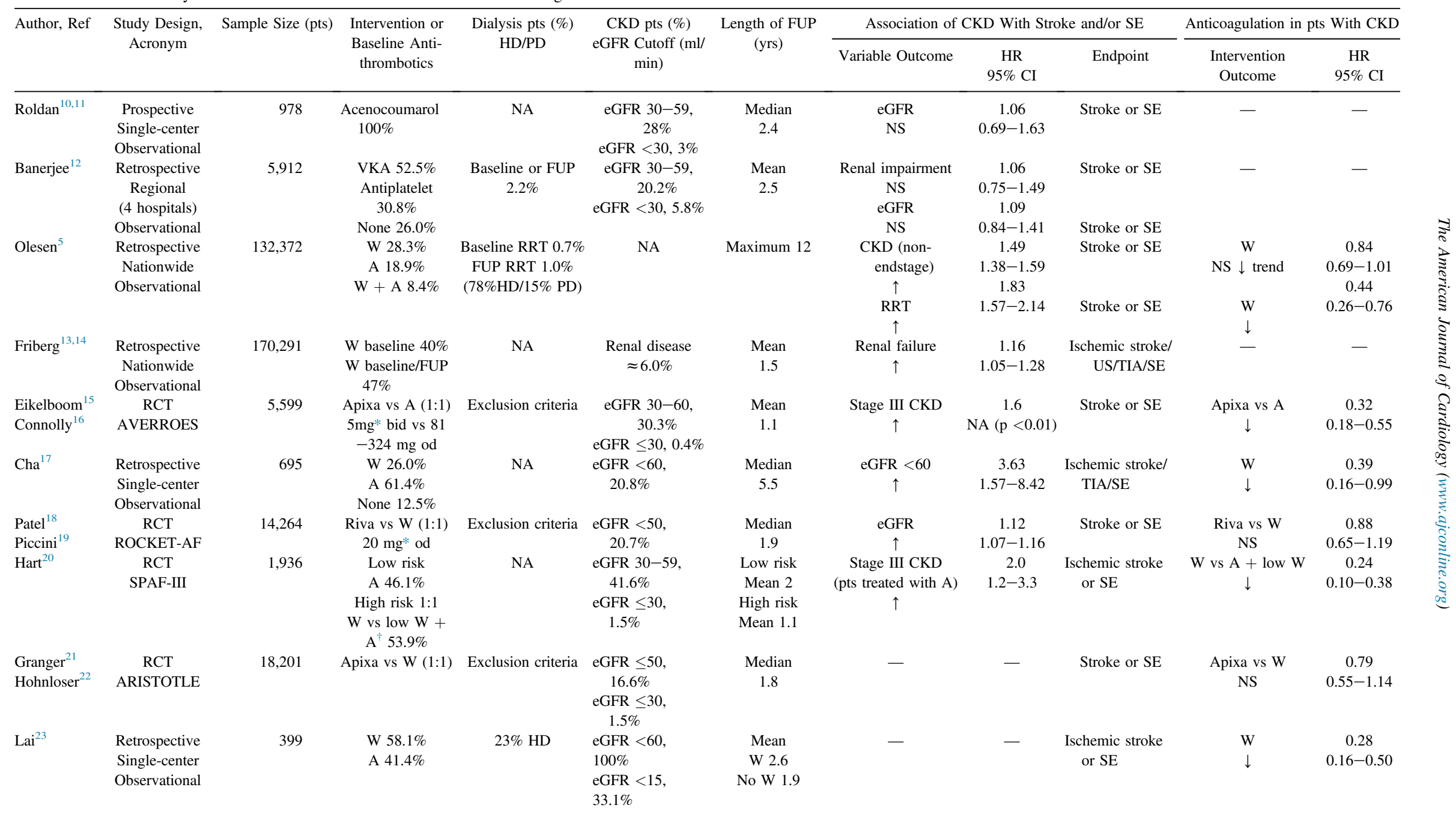




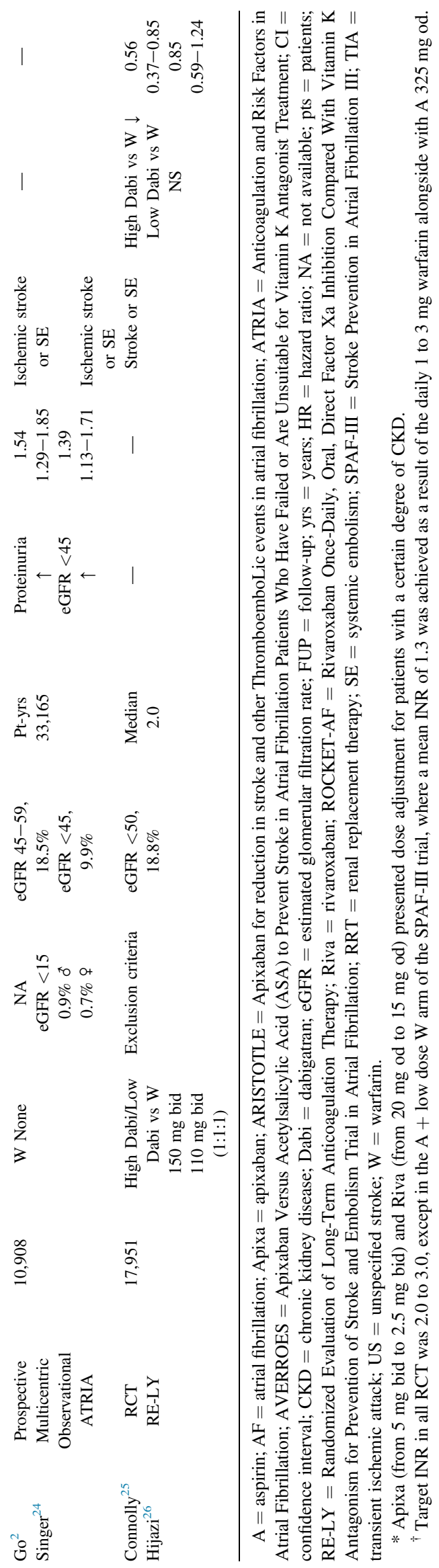

Reporting Items for Systematic Reviews and Meta-Analyses group. ${ }^{7}$ The following data were extracted for characterizing each patient sample in the selected studies, whenever available: criteria for defining CKD, number of patients with CKD (and when available, number in each estimated glomerular filtration rate [eGFR] category of the National Kidney Foundation-Kidney Disease Outcomes Quality Initiative classification $^{8}$ ) or on dialysis in each study, and type and frequency of antithrombotic treatment (warfarin or other vitamin $\mathrm{K}$ antagonists, novel oral anticoagulants, aspirin, or other antiplatelet agents).

Data were pooled using random effects, according to the Mantel-Haenszel model, through Review Manager (RevMan), version 5.1 (The Nordic Cochrane Center, The Cochrane Collaboration, 2011, Copenhagen, Denmark). The measurement of treatment effect and $\mathrm{AF}, \mathrm{CKD}$, or dialysis exposure was performed using dichotomous adjusted hazard ratios (HR) and 95\% confidence intervals (CI). Pairwise comparisons were performed for the primary end point in the settings defined in the third paragraph of the Methods section. Comparison of the treatment effect of adjusted-dose warfarin versus the novel oral anticoagulants was performed through the use of risk ratios (number of events or the incidence in each treatment group) from randomized controlled trials. Additional sensitivity analyses were performed, whenever data were available, regarding end-stage CKD on dialysis treatment. Statistical heterogeneity on each outcome of interest was assessed and quantified using the Cochran Q test and the $\mathrm{I}^{2}$ statistic, respectively. The $\mathrm{I}^{2}$ statistic describes the percentage of total variation across studies due to heterogeneity rather than chance. Values of $<25 \%, 25 \%$ to $50 \%$, and $>50 \%$ are by convention classified low, moderate, and high degrees of heterogeneity, respectively. The presence of publication bias was evaluated through the use of funnel plots if the appropriate requisites concerning the minimum number of included studies in a forest plot were met (at least 10 studies). ${ }^{9}$

\section{Results}

Overall, 962 entries were retrieved for title and abstract analysis. Of these, 783 were excluded as they did not meet inclusion criteria for the meta-analysis and 106 were duplicate entries. The remaining 73 studies were carefully evaluated, and after full-text review, only 19 studies (all full-text reports) were finally considered eligible. ${ }^{2,5,10-26}$ The stepwise selection process is illustrated in Figure 1. There was complete agreement between investigators on the inclusion of all the selected trials. Information on risk stratification, study design, number of participants, and the main findings in each study are provided in Table 1 . Following the predefined inclusion and exclusion criteria, $\leq 5$ studies were included in each of the traced forest plots. Accordingly, no funnel plots were drawn.

Of the selected studies, 10 provided information concerning the impact of CKD on the incidence of stroke or systemic embolism in patients with AF. 2,5,10,12,13,15,17,18,20,21 Different equations were used for estimating the eGFR and classifying patients as having CKD: Cockcroft-Gault formula was used in 5 studies $^{15,18,20,21,25}$ and the Modification of Diet in Renal Disease was used in 5..$^{2,10,12,23,25}$ Also, in 2 investigations $^{21,25}$ the chronic kidney disease epidemiology 


\section{Stroke or systemic embolism in patients with atrial fibrillation}

\begin{tabular}{|c|c|c|c|c|c|c|c|c|}
\hline \multicolumn{3}{|c|}{ Endpoint } & \multicolumn{4}{|c|}{ Hazard Ratio } & \multirow{2}{*}{\multicolumn{2}{|c|}{$\begin{array}{c}\text { Hazard Ratio } \\
\text { IV, Random, } 95 \% \mathrm{Cl}\end{array}$}} \\
\hline \multicolumn{2}{|c|}{ Study or Subgroup | } & log[Hazard Ratio] & SE & \multirow{2}{*}{$\frac{\text { Weight }}{23.6 \%}$} & \multirow{2}{*}{$\frac{\text { IV, Random, } 95 \% \mathrm{Cl}}{1.39[1.13,1.71]}$} & \multirow{2}{*}{$\frac{\text { Year }}{2009}$} & & \\
\hline Go 2009 & IS, SE & 0.32930375 & 0.10570899 & & & & & $\rightarrow$ \\
\hline Hart 2011 & IS, SE & 0.69314718 & 0.2554976 & $10.0 \%$ & $2.00[1.21,3.30]$ & 2011 & & \\
\hline Cha 2012 & IS, US, SE, TIA & 1.28923265 & 0.42927407 & $4.4 \%$ & $3.63[1.56,8.42]$ & 2012 & & \\
\hline Olesen 2012 & IS, SE, TIA & 0.39877612 & 0.03314178 & $31.7 \%$ & $1.49[1.40,1.59]$ & 2012 & & ๘ \\
\hline Friberg 2012 & IS, SE, TIA & 0.14842001 & 0.05022453 & $30.2 \%$ & $1.16[1.05,1.28]$ & 2012 & & $=$ \\
\hline Total $(95 \% \mathrm{Cl})$ & & & & $100.0 \%$ & $1.46[1.20,1.76]$ & & & \\
\hline $\begin{array}{l}\text { Heterogeneity } \\
\text { Test for overal }\end{array}$ & $\begin{array}{l}\operatorname{Tau}^{2}=0.03 ; \\
\text { effect: } Z=3\end{array}$ & $\begin{array}{l}\mathrm{Chi}^{2}=24.39 \\
88(P=0.0001\end{array}$ & $\mathrm{df}=4(\mathrm{P}<0.00$ & 101); $\left.\right|^{2}=8$ & $34 \%$ & & $\begin{array}{lc}1 & 1 \\
0.2 & 0.5 \\
\text { Lower in } & 1 \\
C K D\end{array}$ & Higher i \\
\hline
\end{tabular}

Figure 2. Forest plots illustrating the association of stroke or systemic embolism with the presence of kidney disease in patients with AF. IV $=$ inverse variance; IS = ischemic stroke; SE = systemic embolism; TIA = transient ischemic attack; US = stroke of uncertain origin.

\section{Stroke or systemic embolism in patients with atrial fibrillation and CKD}

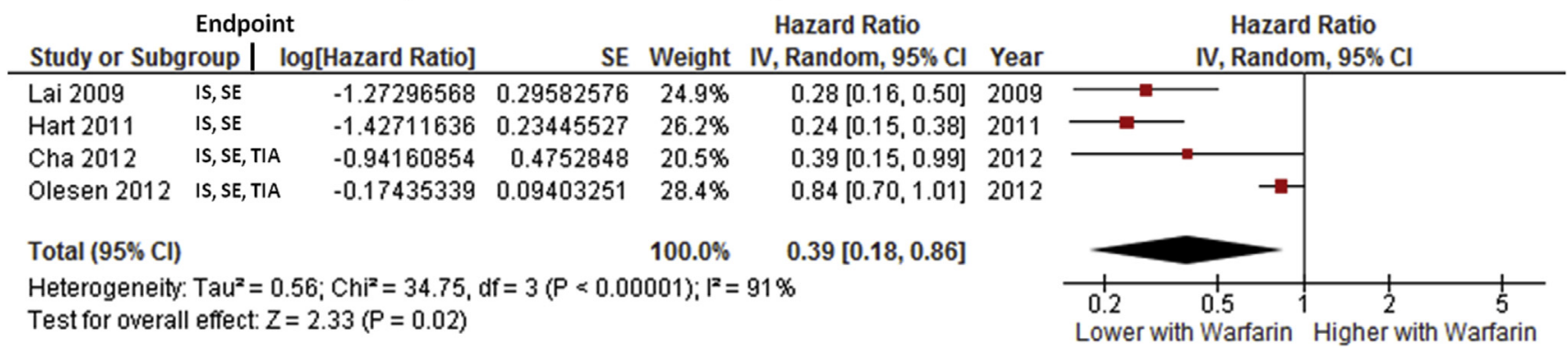

Figure 3. Forest plot illustrating the effect of anticoagulation on the incidence of stroke or systemic embolism in patients with AF and CKD. IV $=$ inverse variance; IS = ischemic stroke; $\mathrm{SE}=$ systemic embolism; TIA $=$ transient ischemic attack.

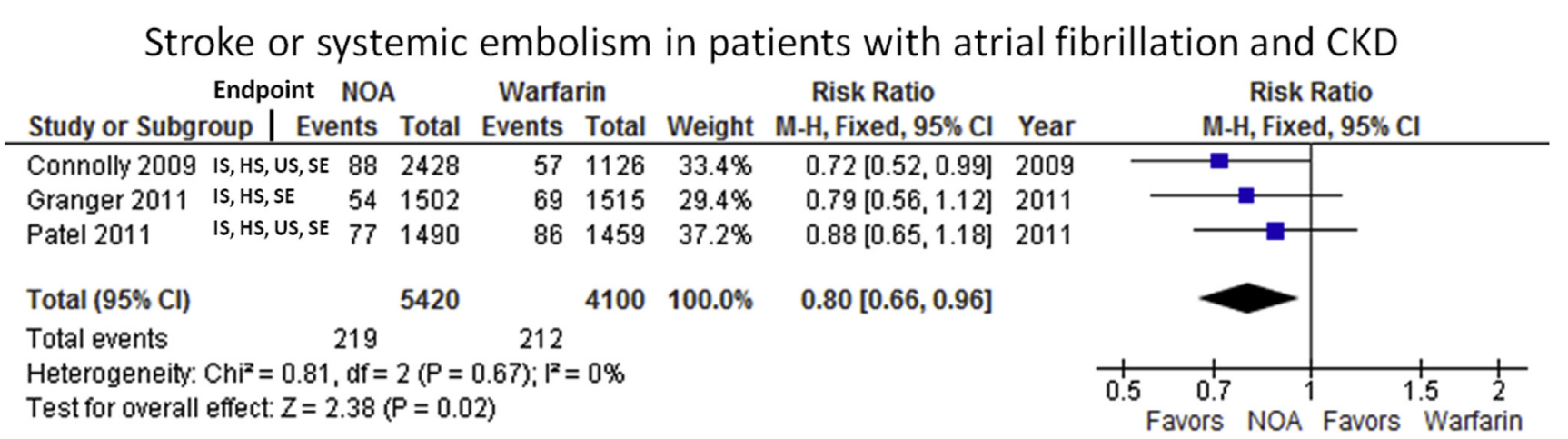

Figure 4. Forest plot illustrating the comparison of warfarin versus the novel oral anticoagulants in the prevention of stroke or systemic embolism in patients with CKD. HS = hemorrhagic stroke; IS = ischemic stroke; $\mathrm{M}-\mathrm{H}=$ Mantel-Haenszel; NOA = novel oral anticoagulants; $\mathrm{SE}=$ systemic embolism; US = stroke of uncertain origin.

collaboration and cystatin C clearance were also used for assessing the safety and efficacy of apixaban and dabigatran at different levels of eGFR. The remaining selected studies for the systematic review did not use any of these, because the diagnosis of CKD was retrieved from codification. ${ }^{5,13,14} \mathrm{~A}$ cutoff of 50 to $60 \mathrm{ml} / \mathrm{min}$ was used in most studies for defining the presence of CKD.

According to data on Figure 2, in patients with AF the presence of CKD was associated with a higher rate of thromboembolic events (HR 1.46, 95\% CI 1.20 to $1.76, \mathrm{p}=$ $0.0001)$. All included studies were in favor of the association of CKD with an increase in thromboembolism in patients with AF. However, their high heterogeneity is shown by the $\mathrm{I}^{2}$ statistic of $\geq 80 \%$. Information concerning the risk of stroke or systemic embolism in patients with $\mathrm{AF}$ who were also on dialysis was provided by only 1 study: in the national Danish registry thromboembolism was found to be increased in this specific population (HR 1.83, 95\% CI 1.56 to $2.14, \mathrm{p}<0.00001)^{5}$

Baseline data, design, and the main findings of trials providing information regarding warfarin in this setting $5,15,17,18,20,21,23,25$ are listed in Table 1. Information concerning time in therapeutic range is only known for the 3 included randomized controlled trials of the novel oral 
anticoagulants controlled with warfarin $(64 \%$ in Randomized Evaluation of Long-Term Anticoagulation Therapy [RE-LY], ${ }^{25} 55 \%$ in Rivaroxaban Once-Daily, Oral, Direct Factor Xa Inhibition Compared With Vitamin K Antagonism for Prevention of Stroke and Embolism Trial in Atrial Fibrillation [ROCKET-AF], ${ }^{18}$ and $62 \%$ in Apixaban for Reduction In STroke and Other ThromboemboLic Events in atrial fibrillation [ARISTOTLE] ${ }^{21}$ trials). As regards the presence of heparin treatment in patients on dialysis, this information was absent or lacked details concerning the protocol used in the included studies.

The use of warfarin was associated with a major decrease in thromboembolic events (HR 0.39 , 95\% CI 0.18 to 0.86 , $\mathrm{p}<0.00001)$ in patients with CKD. The effect was present in all studies but one (which revealed a strong trend for benefit of warfarin; Figure 3). Despite the overall favorable trend, a high heterogeneity, $\mathrm{I}^{2}$ statistic of $91 \%$, was observed driven by the differences in treatment effect. Only 1 study assessing the role of warfarin in the prevention of thromboembolism in patients on dialysis met the inclusion criteria for this meta-analysis. There, warfarin displayed a protective effect (HR $0.44,95 \%$ CI 0.26 to $0.74, p=0.002$ ). Also, the use of warfarin did not lead to an increased risk of bleeding (HR $1.27,95 \%$ CI 0.91 to $1.77, \mathrm{p}=0.15)^{5}$

In Table 1, data concerning renal function subanalysis of 4 randomized controlled trials involving the use of the novel oral anticoagulants in patients with AF are listed. In the Apixaban Versus Acetylsalicylic Acid (ASA) to Prevent Stroke in Atrial Fibrillation Patients Who Have Failed or Are Unsuitable for Vitamin K Antagonist Treatment (AVERROES) trial, aspirin was the treatment of the control arm, and in the others, the RE-LY, ROCKET-AF, and ARISTOTLE trials, warfarin was used. Data concerning the effectiveness of the novel oral anticoagulants versus warfarin and also versus aspirin in patients with CKD (moderate or preterminal CKD) and $\mathrm{AF}$ are shown in Figure 4. A very low level of heterogeneity was found among the 3 selected trials $\left(\mathrm{I}^{2}=0 \%\right)$ showing an overall benefit of the novel oral anticoagulants compared with warfarin (HR 0.80, 95\% CI 0.66 to 0.96, $\mathrm{p}=0.02$ ). Apixaban was more effective than aspirin in preventing stroke or systemic embolism in the non-end-stage CKD population (HR $0.32,95 \%$ CI 0.19 to 0.55 , p <0.0001). In these novel oral anticoagulants trials, only a small minority of patients had eGFR $<30 \mathrm{ml} / \mathrm{min}^{15,21}$ and no patients on dialysis were included.

\section{Discussion}

The observed findings in this meta-analysis suggest an increased risk of thromboembolism when CKD is present in patients with AF, with an incremental relation between the severity of renal dysfunction and the risk of thromboembolism. Anticoagulation seems to be effective in decreasing thromboembolic events in non-end-stage CKD, with a particular benefit of novel oral anticoagulants in the moderate CKD population (eGFR 30 to $60 \mathrm{ml} / \mathrm{min}$ ) with AF. Regarding endstage $\mathrm{CKD}$, data result from a single large national registry and seem in favor of benefit from warfarin. However, data on the novel oral anticoagulants in patients with end-stage or severe $\mathrm{CKD}$ with eGFR $<25$ to $30 \mathrm{ml} / \mathrm{min}$ are currently lacking.
Preliminary evidence has suggested that adding CKD to the currently available risk stratification schemes for thromboembolism in patients with AF may be worth further evaluation. In a subanalysis of the AVERROES trial, when adjusting for the $\mathrm{CHADS}_{2}$ score in multivariate analysis, stage III CKD remained an independent predictor of stroke or systemic embolism (HR 1.6, $\mathrm{p}<0.01){ }^{15}$

Piccini et al have tested the impact of adding CKD to the $\mathrm{CHADS}_{2}$ score and developed the $\mathrm{R}_{2} \mathrm{CHADS}_{2}$ score $\left(\mathrm{CHADS}_{2}\right.$ plus 2 points if creatinine clearance $<60 \mathrm{ml} / \mathrm{min}$ ). This was derived from the ROCKET-AF cohort and validated in the Anticoagulation and Risk Factors in Atrial Fibrillation (ATRIA) study population. They found that, when using the $\mathrm{R}_{2} \mathrm{CHADS}_{2}$ score, almost $20 \%$ of patients were successfully reclassified into a more appropriate risk category (i.e., it improved the net reclassification index by $17.4 \%$ relative to $\mathrm{CHADS}_{2} ; 95 \%$ CI $12.1 \%$ to $22.5 \%$ ), even if $\mathrm{C}$ statistics displayed similar values $\left(\mathrm{CHADS}_{2}=0.673 \mathrm{vs}\right.$ $\left.\mathrm{R}_{2} \mathrm{CHADS}_{2}=0.672\right){ }^{19}$

A score comprising 8 variables (age, previous stroke, female gender, diabetes mellitus, heart failure, hypertension, proteinuria, and eGFR $<45 \mathrm{ml} / \mathrm{min}$ or end-stage renal disease) has been recently derived using data from the ATRIA cohort. Its external validation has shown promising results with higher $\mathrm{C}$ statistics $(0.70 ; 95 \%$ CI 0.67 to 0.72$)$ than the $\mathrm{CHADS}_{2}(0.66$; $95 \%$ CI 0.64 to 0.69$)$ or $\mathrm{CHA}_{2} \mathrm{DS}_{2}-\mathrm{VASc}(0.68 ; 95 \% \mathrm{CI} 0.66$ to 0.70$)$ score for the discrimination of all thromboembolic events. ${ }^{24}$ The discriminative performance of this score was even better if only severe thromboembolic events were considered ( $\mathrm{C}$ statistic $=0.75 ; 95 \%$ CI 0.73 to 0.78$)$, remaining better than $\mathrm{CHADS}_{2}(\mathrm{C}$ statistic $=0.71 ; 95 \% \mathrm{CI} 0.68$ to 0.73$)$ and $\mathrm{CHA}_{2} \mathrm{DS}_{2}-\mathrm{VASc}(\mathrm{C}$ statistic $=0.72 ; 95 \% \mathrm{CI} 0.69$ to 0.74$)$ scores. When assessing the net reclassification improvement obtained by the use of the new score, it was verified that $24 \%$ to $25 \%$ of patients were correctly reclassified into an adequate risk category, compared with $\mathrm{CHADS}_{2}$ and $\mathrm{CHA}_{2} \mathrm{DS}_{2}-\mathrm{VASc}$ scores, respectively (the percentage increased to $33 \%$ if only severe events were measured).

In contrast, different findings were observed by Roldan et al in a smaller population of patients with nonvalvular AF stable on oral anticoagulation for $>6$ months, where adding eGFR (1 point to eGFR 30 to $59 \mathrm{ml} / \mathrm{min}$ and 2 points to $<30 \mathrm{ml} / \mathrm{min}$ ) to the $\mathrm{CHADS}_{2}$ and $\mathrm{CHA}_{2} \mathrm{DS}_{2}$-VASc scores resulted in no significant improvement in $\mathrm{C}$ statistics or integrated discrimination improvement. ${ }^{10}$ In addition, Banerjee et al found that renal impairment and/or eGFR (codified as 3 different categories: $<30,30$ to 59 , and $\geq 60 \mathrm{ml} / \mathrm{min}$ ) did not increase the risk of ischemic stroke or systemic thromboembolism after adjustment for the $\mathrm{CHADS}_{2}$ risk factors. Thus, if added to $\mathrm{CHADS}_{2}$ or $\mathrm{CHA}_{2} \mathrm{DS}_{2}-\mathrm{VASc}$ risk scores, eGFR did not independently add to the predictive value of any of these. $^{12}$

The increased risk of thromboembolism when CKD is present may be explained by the coexistent platelet dysfunction, a prothrombotic and inflammatory state, and more severe vascular disease, frequently found in these patients. ${ }^{2}$ It has also been proposed that the presence of CKD may be a marker of target organ lesion. ${ }^{27}$ Furthermore, an association of low eGFR with an increased prevalence of markers of left atrial stasis (dense spontaneous echocardiographic contrast and low flow velocities in the left atrial appendage) in patients with AF 
on transesophageal echocardiogram may also account for this thromboembolic trend. ${ }^{28}$

Oral anticoagulants were advantageous in the prevention of stroke or systemic embolism in patients with non-end-stage CKD. Among patients on dialysis, the only study assessing the efficacy of warfarin in the prevention of thromboembolism demonstrated a benefit of this drug. ${ }^{5}$ Besides scarcity of data, the increased risk of hemorrhagic stroke in this population when treated with warfarin ${ }^{29}$ may deter the practicing physician from starting anticoagulation.

The observed advantage of the novel oral anticoagulants in the eGFR 30 to $60 \mathrm{ml} / \mathrm{min}$ strata mimics the results observed in meta-analysis of the recent trials involving these agents, ${ }^{30}$ suggesting that their advantage concerning efficacy is maintained despite the presence of moderate CKD. Also, according to data from the subanalysis of the AVERROES trial in the stage III CKD population, apixaban displays a higher efficacy compared with aspirin, with a similar bleeding risk. ${ }^{15}$ However, only a minority of patients with eGFR 25 to $30 \mathrm{ml} / \mathrm{min}$ and none with lower eGFR values have been included in these trials, which does not allow any firm conclusions concerning the use of these agents in those specific types of patients.

There are several limitations to this investigation, which are in part inherent to the meta-analysis method: some of the selected studies were small and the majority was retrospective. Different methods for stroke definition have been used (e.g., with variable usage of imaging), and some uncertainties also remain concerning the chosen AF classification in some studies or even the reliability of its identification. Furthermore, a high heterogeneity of the assessed populations was illustrated by the relatively elevated $\mathrm{I}^{2}$ score in most forest plots.

\section{Disclosures}

The authors have no conflicts of interest to disclose.

1. Lin HJ, Wolf PA, Kelly-Hayes M, Beiser AS, Kase CS, Benjamin EJ, D'Agostino RB. Stroke severity in atrial fibrillation. The Framingham Study. Stroke 1996;27:1760-1764.

2. Go AS, Fang MC, Udaltsova N, Chang Y, Pomernacki NK, Borowsky L, Singer DE; ATRIA Study Investigators. Impact of proteinuria and glomerular filtration rate on risk of thromboembolism in atrial fibrillation: the Anticoagulation and Risk Factors in Atrial Fibrillation (ATRIA) study. Circulation 2009;119:1363-1369.

3. Ezekowitz MD, Bridgers SL, James KE, Carliner NH, Colling CL, Gornick CC, Krause-Steinrauf H, Kurtzke JF, Nazarian SM, Radford MJ, Rickles FR, Shabetai R, Deykin D; the Veterans Affairs Stroke Prevention in Nonrheumatic Atrial Fibrillation Investigators. Warfarin in the prevention of stroke associated with nonrheumatic atrial fibrillation. Veteran Affairs Stroke Prevention in Nonrheumatic Atrial Fibrillation Investigators. N Engl J Med 1992;327:1406-1412.

4. Chan KE, Lazarus JM, Thadhani R, Hakim RM. Warfarin use associates with increased risk for stroke in hemodialysis patients with atrial fibrillation. J Am Soc Nephrol 2009;20:2223-2233.

5. Olesen JB, Lip GY, Kamper AL, Hommel K, Køber L, Lane DA, Lindhardsen J, Gislason GH, Torp-Pedersen C. Stroke and bleeding in atrial fibrillation with chronic kidney disease. N Engl J Med 2012;367: 625-635.

6. Menzies D. Systematic reviews and meta-analyses. Int J Tuberc Lung Dis 2011;15:582-593.

7. Moher D, Liberati A, Tetzlaff J, Altman DG; PRISMA Group. Preferred Reporting Items for Systematic Reviews and Meta-Analyses: the PRISMA statement. Ann Intern Med 2009;151:264-269.

8. IV. NKF-K/DOQI Clinical Practice Guidelines for Anemia of Chronic Kidney Disease: update 2000. Am J Kidney Dis 2001;37:S182-S238.
9. Higgins JPT, Green S, eds. Cochrane Handbook for Systematic Reviews of Interventions Version 5.1.0 [updated March 2011]. The Cochrane Collaboration. Available at: www.cochrane-handbook.org. Accessed on March 2014.

10. Roldán V, Marín F, Manzano-Fernandez S, Fernández H, Gallego P, Valdés M, Vicente V, Lip GY. Does chronic kidney disease improve the predictive value of the $\mathrm{CHADS}_{2}$ and $\mathrm{CHA}_{2} \mathrm{DS}_{2}$-VASc stroke stratification risk scores for atrial fibrillation? Thromb Haemost 2013;109: 956-960.

11. Roldán V, Marín F, Fernández H, Manzano-Fernández S, Gallego P, Valdés M, Vicente V, Lip GY. Renal impairment in a "real-life" cohort of anticoagulated patients with atrial fibrillation (implications for thromboembolism and bleeding). Am J Cardiol 2013;111: $1159-1164$.

12. Banerjee A, Fauchier L, Vourc'h P, Andres CR, Taillandier S, Halimi JM, Lip GY. Renal impairment and ischemic stroke risk assessment in patients with atrial fibrillation: the Loire Valley Atrial Fibrillation Project. J Am Coll Cardiol 2013;61:2079-2087.

13. Friberg L, Rosenqvist M, Lip GY. Evaluation of risk stratification schemes for ischaemic stroke and bleeding in 182678 patients with atrial fibrillation: the Swedish Atrial Fibrillation cohort study. Eur Heart J 2012;33:1500-1510.

14. Friberg L, Benson L, Rosenqvist M, Lip GY. Assessment of female sex as a risk factor in atrial fibrillation in Sweden: nationwide retrospective cohort study. BMJ 2012;344:e3522.

15. Eikelboom JW, Connolly SJ, Gao P, Paolasso E, De Caterina R, Husted S, O'Donnell M, Yusuf S, Hart RG. Stroke risk and efficacy of apixaban in atrial fibrillation patients with moderate chronic kidney disease. J Stroke Cerebrovasc Dis 2012;21:429-435.

16. Connolly SJ, Eikelboom J, Joyner C, Diener HC, Hart R, Golitsyn S, Flaker G, Avezum A, Hohnloser SH, Diaz R, Talajic M, Zhu J, Pais P, Budaj A, Parkhomenko A, Jansky P, Commerford P, Tan RS, Sim KH, Lewis BS, Van Mieghem W, Lip GY, Kim JH, Lanas-Zanetti F, Gonzalez-Hermosillo A, Dans AL, Munawar M, O'Donnell M, Lawrence J, Lewis G, Afzal R, Yusuf S; AVERROES Steering Committee and Investigators. Apixaban in patients with atrial fibrillation. $N$ Engl J Med 2011;364:806-817.

17. Cha MJ, Oh GC, Hahn S, Choi EK, Oh S. Thromboembolic risk evaluation in patients with atrial fibrillation using a modified $\operatorname{CHADS}(2)$ scoring system. J Cardiovasc Electrophysiol 2012;23:155-162.

18. Patel MR, Mahaffey KW, Garg J, Pan G, Singer DE, Hacke W, Breithardt G, Halperin JL, Hankey GJ, Piccini JP, Becker RC, Nessel CC, Paolini JF, Berkowitz SD, Fox KA, Califf RM; ROCKET AF Investigators. Rivaroxaban versus warfarin in nonvalvular atrial fibrillation. N Engl J Med 2011;365:883-891.

19. Piccini JP, Stevens SR, Chang Y, Singer DE, Lokhnygina Y, Go AS, Patel MR, Mahaffey KW, Halperin JL, Breithardt G, Hankey GJ, Hacke W, Becker RC, Nessel CC, Fox KA, Califf RM; ROCKET AF Steering Committee and Investigators. Renal dysfunction as a predictor of stroke and systemic embolism in patients with nonvalvular atrial fibrillation: validation of the $\mathrm{R}_{2} \mathrm{CHADS}_{2}$ index in the ROCKET AF (Rivaroxaban Once-daily, oral, direct factor Xa inhibition Compared with vitamin $\mathrm{K}$ antagonism for prevention of stroke and Embolism Trial in Atrial Fibrillation) and ATRIA (AnTicoagulation and Risk factors In Atrial fibrillation) study cohorts. Circulation 2013;127:224-232.

20. Hart RG, Pearce LA, Asinger RW, Herzog CA. Warfarin in atrial fibrillation patients with moderate chronic kidney disease. Clin J Am Soc Nephrol 2011;6:2599-2604.

21. Granger CB, Alexander JH, McMurray JJ, Lopes RD, Hylek EM, Hanna M, Al-Khalidi HR, Ansell J, Atar D, Avezum A, Bahit MC, Diaz R, Easton JD, Ezekowitz JA, Flaker G, Garcia D, Geraldes M, Gersh BJ, Golitsyn S, Goto S, Hermosillo AG, Hohnloser SH, Horowitz J, Mohan P, Jansky P, Lewis BS, Lopez-Sendon JL, Pais P, Parkhomenko A, Verheugt FW, Zhu J, Wallentin L; ARISTOTLE Committees and Investigators. Apixaban versus warfarin in patients with atrial fibrillation. N Engl J Med 2011;365:981-992.

22. Hohnloser SH, Hijazi Z, Thomas L, Alexander JH, Amerena J, Hanna M, Keltai M, Lanas F, Lopes RD, Lopez-Sendon J, Granger CB, Wallentin L. Efficacy of apixaban when compared with warfarin in relation to renal function in patients with atrial fibrillation: insights from the ARISTOTLE trial. Eur Heart J 2012;33:2821-2830.

23. Lai HM, Aronow WS, Kalen P, Adapa S, Patel K, Goel A, Vinnakota R, Chugh S, Garrick R. Incidence of thromboembolic stroke and of major bleeding in patients with atrial fibrillation and chronic kidney disease 
treated with and without warfarin. Int J Nephrol Renovasc Dis 2009;2: $33-37$.

24. Singer DE, Chang Y, Borowsky LH, Fang MC, Pomernacki NK, Udaltsova N, Reynolds K, Go AS. A new risk scheme to predict ischemic stroke and other thromboembolism in atrial fibrillation: the ATRIA study stroke risk score. J Am Heart Assoc 2013;2: e000250.

25. Connolly SJ, Ezekowitz MD, Yusuf S, Eikelboom J, Oldgren J, Parekh A, Pogue J, Reilly PA, Themeles E, Varrone J, Wang S, Alings M, Xavier D, Zhu J, Diaz R, Lewis BS, Darius H, Diener HC, Joyner CD, Wallentin L; RE-LY Steering Committee and Investigators. Dabigatran versus warfarin in patients with atrial fibrillation. $N$ Engl J Med 2009;361:1139-1151.

26. Hijazi Z, Hohnloser SH, Oldgren J, Andersson U, Connolly SJ, Eikelboom JW, Ezekowitz MD, Reilly PA, Siegbahn A, Yusuf S, Wallentin L. Efficacy and safety of dabigatran compared with warfarin in relation to baseline renal function in patients with atrial fibrillation: a RE-LY trial analysis. Circulation 2014;129:961-970.

27. Hart RG, Eikelboom JW, Ingram AJ, Herzog CA. Anticoagulants in atrial fibrillation patients with chronic kidney disease. Nat Rev Nephrol 2012;8:569-578.

28. Providência R, Fernandes A, Paiva L, Faustino A, Barra S, Botelho A, Trigo J, Nascimento J, Leitão-Marques A. Decreased glomerular filtration rate and markers of left atrial stasis in patients with nonvalvular atrial fibrillation. Cardiology 2013;124:3-10.

29. Winkelmayer WC, Liu J, Setoguchi S, Choudhry NK. Effectiveness and safety of warfarin initiation in older hemodialysis patients with incident atrial fibrillation. Clin J Am Soc Nephrol 2011;6:2662-2668.

30. Miller CS, Grandi SM, Shimony A, Filion KB, Eisenberg MJ. Metaanalysis of efficacy and safety of new oral anticoagulants (dabigatran, rivaroxaban, apixaban) versus warfarin in patients with atrial fibrillation. Am J Cardiol 2012;110:453-460. 